\title{
SOME OBSERVATIONS ON THE BANDING OF GLACIER ICE*
}

\author{
By N. UNTERSTEINER \\ (Institut für Meteorologie und Geophysik der Universität Wien)
}

\begin{abstract}
The distribution of fine banding (foliation) on the surface of a flat glacier tongue was studied. The conclusions reached are that fine banding seems to be neither of sedimentary origin nor to be the representation of a straightforward stress system. In the present case, foliation seems to be connected with ice falls.

Other bands definitely not belonging to the fine banding system were plotted irrespective of their outward appearance. Statistically, their preferred spacial directions correspond to the directions of either maximum shear stress or maximum normal stress (tension).

Zusammenfassung. Die Verteilung der Feinbänderung (Foliation) an der Oberfläche einer flachen Gletscherzunge wird untersucht. Es wird vermutet, dass die Feinbänderung weder sedimentärer Herkunft ist noch die im Gletscher herrschenden Spannungen abbildet. Im vorliegenden Fall erscheint es möglich, dass die Feinbänderung in Zusammenhang mit einem grossen Gletscherbruch steht.

Andere Bänder, die nicht zu dem System der Feinbänderung gehören wurden ohne Rücksicht auf ihre äussere Erscheinungsform kartiert. Statistisch gesehen stimmen ihre bevorzugten Raumrichtungen entweder mit der Richtung der maximalen Schubspannung oder mit der Richtung der maximalen Normalspannung überein.
\end{abstract}

THE problems connected with glacier banding and ice structure have aroused the interest of glaciologists since the scientific study of glaciers began. Although the existing literature on this subject is of a surprising extent (for instance reference 3 ) it seems that some of the problems have become more involved as the studies on glacier mechanics and other branches of glaciology have proceeded. Individual features of single glaciers which may have been unduly generalized and a somewhat confused terminology may have added to this state of affairs. ${ }^{4}$

In the present work we deal with two easily distinguishable kinds of bands.

First, bands which, perhaps not very happily, we have called Feinbänder in German. ${ }^{6}$ These occur in systematic order over the whole glacier surface; they are often particularly well marked near the glacier margin or where two glaciers adjoin. In such cases they are known in German as Pflugfurcheneis. "Parallel Bands"8 or, more appropriately, "Longitudinal Bands"9 have been suggested as the English equivalents. Nevertheless, since this type of banding is only a specialized form of the Feinbänder or Foliation $\uparrow$ we have not used the term Pflugfurcheneis. Macroscopically foliation consists of layers of ice of varying air content and varying translucency. The average thickness of these layers is about $5 \mathrm{~cm}$.

The second kind of bands studied were bands which differed from the fine banding by the fact that they always had different strikes and dips, and furthermore that the distance between them was of the order of metres. Macroscopically, they were mainly layers of clear ice, best described by the term "Blue Bands," and also small cracks with all stages of transition to open crevasses.

Maps were prepared of the spacial distribution of the strike and dip angles of these bands. ${ }^{7}$

As a first example we chose the tongue of the Pasterze Glacier (Eastern Alps, Grossglockner). The part of the tongue where banding was mapped is fed by two main accumulation areas. They are separated from the tongue by a large horseshoe-shaped ice fall. The tongue itself is about $6 \mathrm{~km}$. long and $\mathrm{I} \cdot 2 \mathrm{~km}$. wide, the average slope being $4^{\circ}$.

We measured altogether ten profiles across the glacier, starting from the snout up to the ice falls. Approximately one-third of the glacier's surface is covered by a moraine. In this part no banding measurements were possible (see Fig. I, p. 5०3).

The measurements were carried out by means of a geological compass. The position of each profile was determined by fixing one point at the margin with a theodolite and by keeping the direction as close as possible at right angles to the direction of ice flow. The average length of a profile was $700 \mathrm{~m}$. In each profile we took about one hundred measurements at eighteen localities at an average distance apart of $4^{\circ} \mathrm{m}$.

* Substance of a paper read at the tenth General Assembly of the I.U.G.G., Rome, 1954.

† Mr. George RIGSBY, of SIPRE, Wilmette, Illinois, has proposed the term "foliation," which corresponds in German to B. SANDER's fächige. Parallelgefüge. The term "foliation" is also sometimes uscd in geological literature. Since it comprises nothing but a description of outer appearance it would seem most favourable for the present purpose. 
The measurement of dip and strike of the bands is in itself rather difficult sometimes. One of the most important factors is the weather. In warm rainy weather, for instance, the surface becomes smooth and all kinds of ice structures show up well, whereas in clear sunny weather ablation is fast and most of the finer details are lost in the irregularly melting ice.

The measurement of the direction of strike is comparatively simple and accurate, with the exception of cases in which the inclination of the band is very low. In this case the intersection of the band with the glacier surface is often irregular.

The determination of the angle of dip, that is, the inclination of the band, is much more difficult. Reliable values can only be obtained if there happens to be some kind of vertical exposure such as open crevasses or at least a hummocky surface. Again, low dips tend to give inaccurate measurements. The accuracy of our angle measurements is of the order of $\pm 5^{\circ}$.

These difficulties do not affect the results for the fine banding to a great extent since their dip was always greater than $40^{\circ}$ in the cases investigated.

However, the second kind of banding may well be influenced by the fact that low-dipping structures were not recognized, and furthermore that we may have noted vertical dips too often.

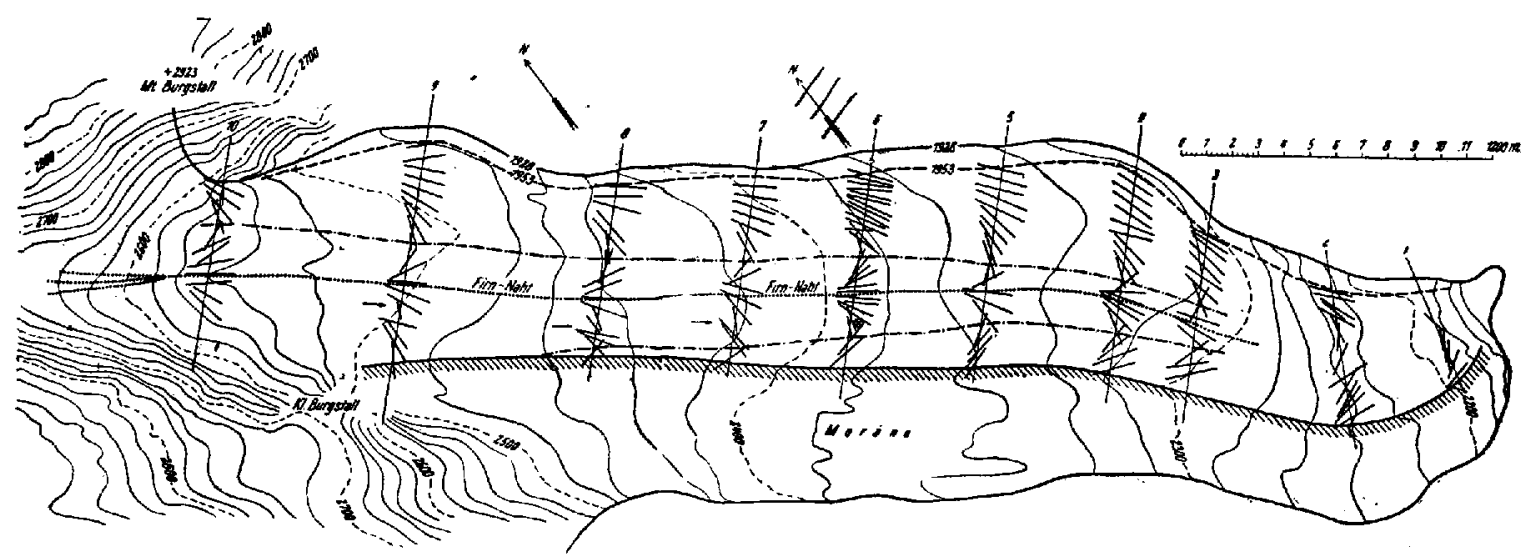

Fig. I. Distribution of angle of strike of "fine bands" on the Pasterze Glacier

It is hoped, however, that from a statistical point of view the results still bring out the essential features of the spacial distribution of this kind of banding.

Besides the measuring difficulties we have to keep a second point in mind which makes the interpretation of any structure of glacier ice to a certain extent problematical. This is the fact that we do not know the relative age of such features, that is to say we can never tell whether, for instance, a tectonic ice band has originated from the stress conditions at the particular spot where it is observed or whether it has been passively transported to this locality. And, moreover, we do not know how long structural features in ice persist.

For a complete interpretation of the bands observed on any spot it would, in theory, be necessary to retrace the history of this ice back to its origin.

The problem of the relative age of ice structures would be greatly simplified if it were true that most of them do not extend beyond a certain depth in the glacier. Assuming this depth to be 30 $\mathrm{m}$., and assuming a yearly movement of $20 \mathrm{~m}$. and an ablation of $3 \mathrm{~m}$., it would mean that a structure once formed would exist only for a period of ten years, that is, that it would move only $200 \mathrm{~m}$. on the glacier. If this were so one would be justified in relating structures to the conditions in the area of their occurrence. From this point of view it would be very important to learn more about the existence of ice bands in the interior of a glacier tongue like the Pasterze. 
When we began our studies on this glacier we descended into several glacier mills, but unfortunately, we were not able to proceed further than a depth of $27 \mathrm{~m}$. since all of them contained a considerable amount of water. However, at this depth we could observe no change in the general features of ice structure. 6

Fig. I shows the results of the measurements of fine banding. The strike is shown by the heavy black lines. For the sake of clarity the angles of dip are not indicated. From the strike distribution one gets the impression that the fine banding forms two arcs. (There seems to be a third arc beneath the debris-covered part of the glacier where, as mentioned, no measurements could be made.) The dip distribution ${ }^{7}$ shows that near the margin the fine bands are nearly parallel to the glacier bed having a dip of approximately $40^{\circ}$. Following the arc round to its apex the dips remain more or less unchanged, becoming steeper as we approach the next arc. The actual place where the next arc sets in is characterized by vertical dips. This line is known on the Pasterze as the Firn-Naht. Firn-Naht (literally firn suture) because the ice here is extremely fine-grained and has an almost firn-like appearance the origin of which is a problem in itself. 7 From this line on dip decreases, reaching a minimum at the apex of the second arc and then steepening again towards the third and hidden arc.

From this we can see that the fine banding is arranged in a spoon-like shape, and, as we see from the map, a similar pattern is retained throughout the whole length of the glacier tongue.

The dips, however, undergo a very significant change from the highest to the lowest profile. We find very steep dips of sometimes $90^{\circ}$ at the apices of profiles Io and 9. This value decreases gradually towards the lower profiles but is never less than $35^{\circ}$, measured from the glacier surface.

We tried to find an explanation for this distribution of the fine banding, hoping at the same time to obtain more evidence about its physical nature and origin. ${ }^{7} \mathrm{~W}$ ithout going into more details we may summarize the conclusions reached.

It seems most unlikely that the fine banding is inherited firn stratification from the accumulation areas, that is, of sedimentary origin. Before reaching the flat glacier tongue the ice has to pass through big falls where its thickness probably does not exceed $40 \mathrm{~m}$. and where fracturing and irregular movement goes right down to the bottom. Furthermore, it seems quite impossible that the system of fine banding represents some sort of a slip-line field. Relative movement along the double or triple spoon-shaped fine bands could never correspond with the known normal velocity distribution of the whole glacier.

We therefore received the impression that the fine banding forms in a zone of transition between the disturbed flow in the ice falls and the steady flow in the flat tongue. The most unexplainable feature of this banding distribution is the very steep dip in the uppermost profiles.

It seems that by this investigation we have only been able to exclude two simple possibilities. First, the fine banding being of sedimentary origin and, second, the fine banding reflecting a straightforward stress system.

Naturally, fine banding systems can always act as shear planes under favourable stress conditions, for instance at the margin of the glacier.

The second kinds of banding investigated were crevasses, cracks and blue bands which ran in directions other than the fine banding system. These bands were plotted irrespective of their outer appearance. Since it is one of their essential features that they are less frequent on the glacier a different technique of plotting was used.

In order to get a comparable net of observations the distance of each measuring point from the margin was divided by the whole width of the glacier in this profile. Using these reduced distances we then divided the left half of the glacier into three longitudinal strips, the first strip extending from the margin to a distance ratio of $0 \cdot 20$, the second strip overlapping from $0 \cdot 16$ to 0.35 , and the third again overlapping from $0.3 \mathrm{I}$ to 0.60 .

The measurements of each strip can thus be collated into one diagram. In order to show the spacial distribution of the bands this was done in a Schmidt net (as used in petrofabrics). Each of 
the three diagrams (Figs. 2, 3, 4, below) contains about $13^{\circ}$ points, the density of which is shown by the contour lines. This can be done on the Schmidt net since it is true to area.

Fig. 2 shows the band distribution in the marginal zone. The direction of general glacier flow is indicated by the heavy arrow.

It is possible to distinguish three maxima of band directions. One pronounced maximum is found at the circumference. It corresponds to the direction of crevassing-C. Another strong maximum represents bands dipping at $60^{\circ}$ against the direction of ice movement. A third maximum corresponds to planes approximately perpendicular to the glacier's margin. All other features of the diagram are of no significance.

As we see, the directions of the bands seem to be in no way irregular. Therefore we may try to give a few indications of the mechanics of their formation. $\mathrm{Nye}^{5}$ has recently shown how the main stresses in a symmetrical glacier are directed, and in which way crevassing is to be expected in various zones.

In the case of Pasterze it can obviously be assumed that compressive flow, in the sense of Nye, occurs since the glacier bed is concave and ablation is great.

One main normal stress is compressive and points towards the margin at an angle of approximately $45^{\circ}$. The second main normal stress is tensile and causes crevassing parallel to the first main normal stress. Nye's results correspond well with what can generally be observed on a flat glacier tongue.
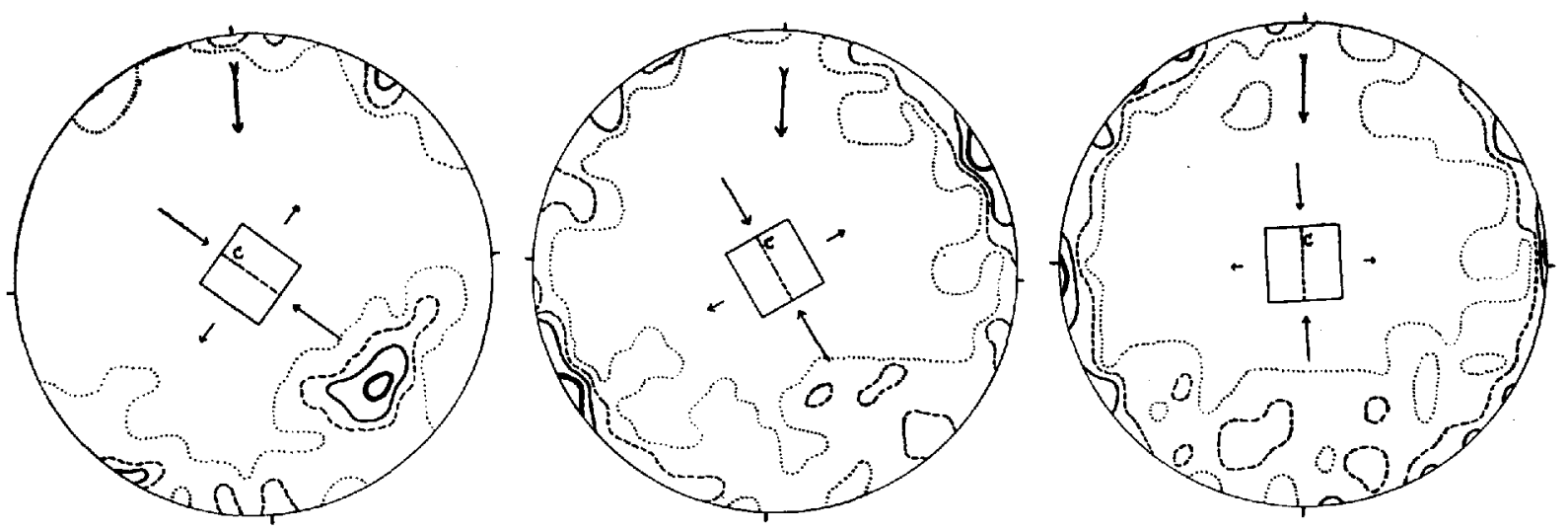

Fig. 2 (left). Distribution of orientation of bands other than fine bands within a strip from the glacier margin to 0.2 of the width. A Schmidt projection has been used. Contours show density of points at 2, 4, 7 and Io. The heavy arrow indicates the general direction of glacier movement. The directions of principal stresses and crevassing are shown in the centre

Fig. 3 (centre). Distribution of orientation of bands other than fine bands within a strip from 0.16 to 0.35 of the glacier width

Fig. 4 (right). Distribution of orientation of bands other than fine bands within a strip from 0.31 to 0.60 of the glacier width

For our purpose we may now, in turn, take the easily observable direction of crevassing as an indicator as to how the main stresses are orientated.

Corresponding to the two main normal stresses we would have altogether six directions of maximum shear stress in which gliding could theoretically be expected. Considering the general direction of movement and some restricting conditions at the margin, Nye has pointed out that we cannot hope to find all shearing directions equally well developed.

It is possible to account for most of the features of the band distribution shown in Figs. 2, 3, 4 if we consider them either as crevasses and related to them or as shearing planes.

In the centre of Fig. 2 the main normal stress directions are drawn. $\mathrm{C}$ indicates the direction 
of crevassing. The corresponding maximum in the graph is found at the circumference. Of the two vertically dipping shear planes only one is shown by the bands, the corresponding maximum also being at the circumference. It seems rather surprising that relative movement should occur in this direction since the bands meet the glacier bed at a right angle. The second symmetrical shearing direction is in this case nearly parallel to the fine banding and this may be the reason why the second kind of banding does not develop here. A third maximum lies in the lower right-hand sector of the diagram. It corresponds to a direction of maximum shear stress at $45^{\circ}$ to the main compressive stress. Actually, the banding maximum is at $60^{\circ}$, but the whole technique of these measurements is not sufficiently accurate to discuss such comparatively small deviations from the idealized conditions.

Fig. 3 shows the banding measurements at a distance ratio of 0.16 to 0.35 from the margin. The stresses as indicated in the centre of the graph show a clockwise rotation towards the longitudinal axis of the glacier. The crevasses $\mathrm{C}$ are again indicated by a strong maximum with an elongation towards the point where one of the vertically dipping shear planes could be expected. Symmetrically to it the second shearing direction is well shown in the diagram. The maximum in the lower right-hand sector is weaker now but still clearly distinguishable. A new maximum in the lower left-hand sector would correspond to shearing by the tensile stress component.

Fig. 4 represents banding between a distance ratio of $0.3 \mathrm{I}$ to 0.60 . According to the direction of crevassing the stress system is now almost parallel to the longitudinal glacier axis. The theoretical results of Nye show that this condition should have been present much before reaching the central strip of the glacier. In his case of compressive flow there should be no tensile stress component in the central zone. In the case of the Pasterze this may, however, not apply since the whole glacier surface is slightly inclined towards its left side, that is, the side where our measurements were taken. The zone of zero tensile stress may therefore be shifted towards the right side of the glacier. In Fig. 4 we again find the vertically dipping shearing planes represented by four maxima at the circumference. The maximum of the lower right-hand sector (Figs. 2, 3) appears in the centre of the lower half now and is much less pronounced.

While in the case of find banding we have been unable to offer any well founded suggestion as to its origin the type of banding shown in the last three figures seems to be explainable and in fair agreement with our knowledge of the acting stresses in a glacier.

This seems to be not a surprising result. It would be much more interesting to know something about the relative importance of bands and shearing planes within the general movement of the glacier. For this purpose the most helpful course would be to undertake actual measurements of relative movement. This would certainly be attended with certain technical difficulties since one would have to measure not only horizontal but also vertical components of movement.

In addition to that it would, of course, be necessary and most interesting in many other respects too, to carry on petrofabric studies of ice to a much greater extent than have so far been done.1,2, 6 $M S$. received I9 October 1954

\section{REFERE NCES}

I. Bader, H. Introduction to ice petrofabrics. Fournal of Geology, Vol. 59, No. 6, 1951, p. 519-36.

2. Rigsby, G. P. Crystal fabric studies on Emmons Glacier, Mount Rainier, Washington. Fournal of Geology, Vol. 59, No. 6,1951, p. $590-98$.

3. Dobrowolski, A. B. Glaciers, Structure and Movement Theories. (Chapters I 3 and 14 of the author's Historia Naturalna Lodu, Warsaw I 923.) Warsaw, Institute for Experimental Physics, I 948, I I p.

4. Glacier Bands, Conference on Terminology. Fournal of Glaciology, Vol. 2, No, 13, 1953, p. $229-32$.

5. Nye, J. F. The mechanics of glacier flow. Fournal of Glaciology, Vol. 2, No. 12, 1952, p. $82-93$.

6. Schwarzacher, W., and Untersteiner, N. Zum Problem der Bänderung des Gletschereises. Sitzungsberichte der Österreichischen Akademie der Wissenschaften, Mathematisch-naturuissenschaftliche Klasse, Abt. 2a, Bd. 162, Ht. I-4, I 953 , p. I I I -45 .

7. Untersteiner, N. Über Feinbänderung und Bewegung des Gletschereises. Archiv für Meteorologie, Geophysik und Bioklimatologie, Serie A. Meteorologie und Geophysik, Bd. 7, I954, p. 23 I-42.

8. See Fournal of Glaciology, Vol. I, No. 6, 1949, p. 333.

9. Reference 4 , p. 230 . 